\title{
Una mirada al Concilio. \\ Desde la recepción de su antropología en los sínodos de Temuco
}

\author{
Tibaldo Zolezzi $C$. \\ INSTITUTO DE ESTUDIOS TEOLÓGICOS \\ UNIVERSIDAD CATÓLICA DE TEMUCO
}

A casi ya cincuenta años de su celebración, es oportuno y posible verificar la acogida que el Concilio Vaticano II va teniendo en la base eclesial. Para hacerlo nos ha parecido pertinente mirar su enseñanza antropológica y cómo ella ha sido recepcionada por la Iglesia en estos años de posconcilio que llevamos.

Sabemos cada día más, y nos lo muestra lo que va sucediendo con el mismo Vaticano II, que la recepción de un Concilio constituye un momento integrante y privilegiado para su interpretación ${ }^{1}$. Sabemos también que en el Concilio Vaticano II encontramos una rica antropología, que, al interior del mismo, se constituye en un verdadero núcleo articulador de toda su enseñanza; y que, formulada sistemáticamente en la Constitución Gaudium et Spes con la intención de enriquecer el diálogo de la Iglesia con el mundo, ha sido entregada a la Iglesia y al mundo como gran servicio del Concilio a la humanidad contemporánea ${ }^{2}$.

El Concilio entiende al hombre como una realidad abierta a la trascendencia. Creado a imagen de Dios y elevado a participar de la natura-

1 Es mucho lo que se ha escrito sobre la recepción del Concilio. Aquí solo destaco tres artículos correspondientes a épocas distintas: G. ALBERIGO, «La condición cristiana después del Vaticano II», en G. ALbERIGO - J. P. JOSSUA, La recepción del Vaticano II (Madrid 1987) 17-45; G. AlbeRIGO, «El Vaticano II y su herencia», Selecciones de Teología 35, 139(1996), 175-185 y P. HÜNERMANN, «El “texto” pasado por alto. Sobre la hermenéutica del Concilio Vaticano II", Revista internacional de Teología Concilium 312 (2005) 139 (579) - 159 (599): el autor alude críticamente a la distinción de tres hermenéuticas respecto del Vaticano II, a saber, la hermenéutica de los autores, la hermenéutica del texto y la hermenéutica de los receptores.

2 Cf. Gaudium et Spes 12 
leza divina ${ }^{3}$, como sujeto de una vocación sublime ${ }^{4}$, que tiene en Cristo su fuente y su corona ${ }^{5}$. Y ello en la perspectiva de una interpretación personalista y solidaria de quien, estando en el mundo, está llamado a transformarlo y transformarse a sí mismo ${ }^{6}$.

En este trabajo hemos querido contrastar dicha enseñanza con la reflexión teológico pastoral de los dos Sínodos celebrados en la Diócesis de Temuco luego del Concilio 7 . Estos sínodos reflejan en algunos aspectos una comprensión levemente diversa de la antropología conciliar. Esta diversidad tiene que ver ciertamente con las urgencias propias de épocas distintas, pero también $-y$ aquí radica lo sorprendente de nuestro resultado-, con lo poco conclusa de la antropología del Vaticano II.

Habrá que admitir entonces que, desde su recepción, es posible reconocer al mismo tiempo riquezas y aportes, pero también lagunas y límites, en la antropología que ofrece el Vaticano II. Lejos de un discurso acabado el Concilio ofrece pistas de reflexión, a veces solo enunciadas y de modo tan abierto, que ha sido posible derivar de él afirmaciones hasta contradictorias. Ello explica en gran parte los vaivenes que manifiesta su recepción.

\section{LOS SÍNODOS DE LA IGLESIA DE TEMUCO}

Estos sínodos reflejan el espíritu de épocas sociales y eclesiales distintas: el paso de una época fuertemente antropológica a una más eclesiológica. La primera, marcada por el mismo Concilio, la segunda por el programa de Nueva Evangelización del papa Juan Pablo II. La Asamblea possinodal del 2006, de la cual también tratamos en este trabajo, pareciera reflejar una tercera época, caracterizada por una vuelta a lo antropológico desde una perspectiva más cristocéntrica.

3 Cf. LG 2 y GS 13

4 Dignitatis humanae eximia ratio in vocatione hominis ad communione cum Deo consistit (GS 19).

5 Cristo es confesado como fundamento y cumbre de la verdad sobre el hombre: GS $22 ; 32 ; 38$

6 Cf. los capítulos I, II y III de la primera parte de Gaudium et Spes.

7 El primero en el año 1968 y el segundo entre los años 1994 y 1995. En este trabajo se incluye también la Asamblea postsinodal celebrada en 2006 al cumplirse los 10 años de la celebración del segundo Sínodo. 
El Sínodo del año 1968 constituye una primera recepción del Vaticano II, inmediata y muy próxima del hecho conciliar: al igual que en la mayoría de la diócesis del país, una vez concluido el Concilio Vaticano II, se celebró en Temuco un Sínodo para renovar la Iglesia diocesana en el espíritu de este Concilio. Lo que se conserva de este Primer Sínodo es un texto resumen de sus acuerdos ${ }^{8}$. Encontramos en él una somera descripción de la hora presente, definida como hora de "transformaciones históricas profundas y veloces y de fuertes tensiones intelectuales y sociales» en la que «muchos hombres angustiados por la incertidumbre, pierden la fe y la esperanza en todo" y en la que "el amor entre los hombres se pierde o se busca con violencia» (página 5). El Sínodo constituye una primera lectura entusiasta del magisterio del Vaticano II. El conjunto de sus acuerdos refleja una comprensión sinodal de la pastoral y una clara orientación de servicio al mundo: se pone un fuerte acento en la promoción humana y se manifiesta el deseo de participar en las tareas del desarrollo de la sociedad.

El Segundo Sínodo se celebró en dos etapas. La primera, durante 1994, consistió en la realización de encuentros de reflexión en las bases, en la aplicación de una consulta o encuesta extraeclesial, en la tabulación del fruto de ambas acciones y en la preparación del Documento de Trabajo sinodal. La segunda, durante 1995, consistió en la celebración de tres Asambleas Sinodales y en la preparación y promulgación del documento final ${ }^{9}$. Este Sínodo se realizó en el contexto de una década

8 Que lleva por título Acuerdos del Sinodo pastoral de Temuco 1968. Se trata de una síntesis preparada por el obispo Bernardino Piñera Carvallo. Su estructura consiste en una introducción y tres partes: la Iglesia como comunidad, los tres ministerios, y las estructuras diocesanas. Son 142 los acuerdos del Sínodo presentados de manera bastante escueta y telegráfica, lo que facilita su comprensión y aplicación inmediata, pero deja poco espacio para profundizar en su fundamentación.

$9 \quad$ Lleva por título Con Cristo caminamos al Tercer Milenio y fue promulgado con fecha 8 de diciembre de 1995. Aparece estructurado en cinco partes. La primera se refiere al contexto Diocesano, la segunda habla del personal apostólico, la tercera está dedicada a las estructuras para la pastoral de conjunto. La cuarta parte, titulada Nueva evangelización en la Diócesis de Temuco, se subdivide en dos grandes secciones: la primera alude al contexto general y habla de la tarea evangelizadora, la situación de la misma en la Diócesis y de la nueva evangelización; la segunda sección desarrolla distintos temas específicos. La quinta parte, que lleva por título Iglesia en el mundo, también se estructura en dos secciones: la primera hace una presentación global de la misión de la Iglesia centrada en la proclamación e inauguración del Reino de Dios, y reflexiona los signos de los tiempos de final del milenio perceptibles en la 
marcada por profundos cambios culturales. Lo manifestó el obispo Sergio Contreras en la Carta convocatoria: el mundo realiza cambios muy acelerados que comienzan a tener profundas manifestaciones en nuestra región. Hablamos que está naciendo una nueva era, que emerge una nueva cultura... También lo manifiesta el Documento Final del Sínodo que define el presente como una época de profundos y vertiginosos cambios culturales, sociales, económicos, políticos y técnicos $(33 ; 34 ; 389)$. Si bien es cierto que su discurso teológico pastoral transcurre, en su forma, más cercano al método empleado en el Documento de Santo Domingo que al empleado, por ejemplo, en Gaudium et Spes, pues en cada tema se parte de una «reflexión doctrinal», luego se discierne la «situación social y eclesial», para, finalmente, entregar "propuestas de acción pastoral $»^{10}$, es indudable que la reflexión de este Sínodo tuvo al Concilio como referente principal: lo muestra el recurso frecuente al mismo ${ }^{11}$ y la centralidad que el Vaticano II tiene en el desarrollo de la reflexión doctrinal de cada uno de los temas incorporado en el debate Sinodal.

La Asamblea postsinodal de 2006 fue la culminación de un proceso de evaluación de la aplicación de las conclusiones del II Sínodo Diocesano $(1 ; 14 ; 40)$ : al cumplirse 10 años desde su celebración se quiso mirar los nuevos desafíos de la historia y redescubrir la vigencia de las conclusiones del mismo (44). Antes de su celebración se realizó una etapa de consulta, en un verdadero espíritu sinodal, sobre el quehacer y el modo de ser de la Iglesia diocesana de Temuco en este tiempo (4; 25; 56). Las deliberaciones de la Asamblea quedaron recogidas en un Docu-

Región de la Araucanía; la segunda sección menciona distintos ámbitos específicos. El texto está subdividido en 967 párrafos.

10 Mons. Sergio Contreras Navia, al convocar el Sínodo, indica al Documento de Santo Domingo como inspirador del mismo: «Así como en 1968, el Sínodo Diocesano aplicó el Concilio, renovando la Iglesia de Temuco, hoy haremos algo semejante aplicando Santo Domingo. Permaneceremos, por supuesto, fieles al Concilio, como Santo Domingo permanece fiel. Pero miraremos seriamente cómo aplicaremos a nuestra realidad concreta, esas orientaciones generales dadas para todo el continente» (Carta de monseñor Sergio Contreras N., obispo de Temuco, convocando al Sínodo diocesano 1994-1995).

11 A lo largo del Documento el Concilio Vaticano II es citado 166 veces. Es más mencionado que el magisterio del papa Juan Pablo II, que aparece citado o referido, ya sea de forma directa o indirecta, 100 veces. Y más que el Documento de Santo Domingo, que aparece citado o referido 75 veces. 
mento Final ${ }^{12}$. En él se manifiesta la convicción de que vivimos en una nueva época y cultura antropológica, caracterizada por el primado de la experiencia y de la relación, que no deja de sorprender y hasta sobrepasar a la misma Iglesia. Época y cultura en la que las personas manifiestan otras formas de percibir su ser y quehacer en el mundo, otros modos de relacionarse $(18 ; 87)$ con Dios, consigo mismo, con los demás, con el mundo y con la historia (135).

\section{RIQUEZAS Y LÍMITES DE LA ANTROPOLOGÍA DEL VATICANO II}

Cuando miramos los núcleos centrales de la propuesta antropológica del Concilio a la luz de cómo ellos han sido acogidos, olvidados o profundizados por los Sínodos de la Diócesis San José de Temuco, asoma tanto la conciencia de las grandes aportaciones de esta propuesta, como también la existencia de profundos vacíos en la misma.

El ejercicio realizado nos ha permitido reconocer cuatro situaciones respecto de estos núcleos centrales de la antropología del Vaticano II: primero, que la enseñanza antropológica del Concilio se dio en sintonía con el dinamismo de la época, con la que se quiso dialogar, a veces sin un claro discernimiento, haciendo de lo antropológico y de la problemática de la dignidad humana una perspectiva central y una preocupación permanente; segundo, que en su propuesta antropológica el Concilio no logró superar los seculares temores de la Iglesia respecto de la autonomía del mundo y de la libertad humana; tercero, que el Concilio no desarrolló con amplitud y profundidad lo que constituye lo más propio de la antropológica cristiana y, por tanto, el mayor aporte que la Iglesia puede dar al devenir de la humanidad, esto es su fundamentación teológica y cristológica; y, finalmente, en razón de lo mismo, que la riqueza original de la propuesta antropológica del Vaticano II, a saber, la valoración de la historia humana y la íntima vinculación de la misma con la historia

12 Que lleva por título Actas Asamblea Post-Sinodal. Nuestra participación en "Aparecida". Diócesis de "San José" de Temuco, y está fechado en octubre de 2006. Está estructurado en tres secciones: una introducción, una reflexión en torno a la conciencia que surge una nueva cultura y luego el resultado de la profundización de las voces surgidas desde las fichas de consulta. Esta última sección, luego de una presentación introductoria, recoge cinco temas: testimonio, acogida, misión, formación, catequesis y liturgia. Cada uno de ellos es presentado según el método ver -juzgar- actuar: se parte de la situación, luego se presenta una reflexión teológicopastoral, para, finalmente, señalar un conjunto de propuestas. 
de la salvación, fue expresada de tal modo que está siendo prontamente olvidada por la misma Iglesia.

\section{EN SINTONÍA CON EL DINAMISMO DE LA ÉPOCA}

\section{Giro antropológico}

El Concilio hizo de lo antropológico un centro, nos quiso entregar una imagen cristiana del hombre y con ello descubrir al hombre su propio ser. Esto lo manifiesta expresamente el Vaticano II, por ejemplo, en la misma Gaudium et Spes y también en la declaración Nostra Aetate ${ }^{13}$. De esta manera, el Concilio «se desarrolló en sintonía con el gran debate sobre el hombre que ha caracterizado a la modernidad y buscó redefinir la relación entre la Iglesia y ciertos elementos esenciales del pensamiento moderno: los tiempos estaban maduros para eso, se había pasado de un inicio de relación muy problemático entre la Iglesia y la modernidad a un paulatino abrirse el uno al otro» ${ }^{14}$.

Sin embargo algunos se preguntan si el antropocentrismo del Vaticano II no habrá sido una excesiva e ingenua concesión de la Iglesia a la modernidad, con la cual quería reencontrarse y dialogar. De hecho la Iglesia del Concilio parece hacer suyo el credo de la modernidad, y lo hace, hoy lo podemos percibir, de manera bastante acrítica, cuando afirma, por ejemplo, que creyentes y no creyentes están generalmente de acuerdo en este punto: todos los bienes de la tierra deben ordenarse en función del hombre, centro y cima de todos ellos (GS 12); y cuando, en el mismo sentido, enseña que es a través del hombre que el universo material

13 Ver GS 3; 10; 11; NAe 1.

14 Palabras del papa Benedicto XVI, en discurso a la curia romana del 22 de diciembre de 2005, recordando los cuarenta años del término de los trabajos conciliares. El texto completo lo encontramos en: http://www.vatican.va/holy_father/benedict_ xvi/speeches/2005/december/documents/hf_ben_xvi_spe_20051222_roman-curia_sp.html. Lo mismo había dicho ya Pablo VI en su discurso del 7 de diciembre de 1965, en la Sesión Pública con que se clausuró el Vaticano II: habló de «nuestro nuevo humanismo», de «nuestro culto al hombre», y justificó al Concilio del reproche de desvío «hacia las posiciones antropocéntricas adoptadas por la cultura moderna». Este discurso lo encontramos en Concilio Vaticano II. Constituciones. Decretos. Declaraciones. Legislación posconciliar (Madrid 1966) 1067-1073. 
alcanza su perfección ${ }^{15}$. Hoy por hoy, y desde una renovada conciencia evolutiva y ecológica, muchos no están de acuerdo con esta afirmación ${ }^{16}$.

Ahora bien, el antropocentrismo del Concilio está bien fundado en la misma revelación, pues se trata de un antropocentrismo teónomo. Efectivamente, la Iglesia se vuelve hacia el hombre y lo hace medida de su misión pastoral, viéndolo en su relación con Dios y como alcanzando su integridad solo a base de reconocer y honrar esta relación. El gran tema que traspasa toda la constitución pastoral es precisamente la vocación del hombre a la comunión de la vida divina, tal vocación es para el Concilio la propuesta fundamental en su diálogo y servicio al mundo ${ }^{17}$.

La reflexión teológico pastoral de los sínodos de Temuco continúa y explicita este giro antropológico del concilio al vincular estrechamente evangelización y promoción humana. Y también al fundar desde un antropocentrismo bíblico y teológico la preocupación por el medio ambiente y la ecología.

Respecto de lo primero, el Sínodo de 1968 pone un fuerte énfasis en que la tarea de la promoción humana compete a todo creyente y a la Iglesia en su conjunto. Manifiesta el deseo de un laicado «...comprometido en particular en la lucha de los hombres por el desarrollo, la cultura, la promoción, la justicia y la paz» (Introducción 3. 1). Propone «que los cristianos seamos los primeros en abrir paso a nuevas estructuras, si las hay, capaces de asegurar una mayor producción, una mayor distribución de los bienes y una mayor participación de todos los hombres en la orientación de la economía al servicio de la persona humana» (4.9). Invita a empeñarse «... en el estudio, en el trabajo y en el ahorro para sacar al país del subdesarrollo con nuestro propio esfuerzo» (4. 12). A entender como deber todo lo que contribuye «a la educación e instrucción de los niños, al desarrollo integral de la personalidad, a la integración de los marginados -especialmente los campesinos-; al desarrollo industrial de la zona» (8. 13).

15 LG 48,1; GS 14,1; AA 7, 2.

16 Como lo señala, por ejemplo, L. VISCHER, «El ser humano, ¿̨centro y cima de la tierra?», Revista internacional de Teología Concilium 312 (2005) 175 (615) - 179 (619).

17 Son palabras del P. Congar, gran teólogo del Vaticano II: cf. Yves M.-J. CongaR, «Iglesia y Mundo en la perspectiva del Vaticano II», en Vaticano II. La Iglesia en el mundo de hoy. Constitución Pastoral Gaudium et Spes, Tomo III: reflexiones y perspectivas (Salamanca 1970) 17-45. 
En el segundo Sínodo se afirma la existencia de lazos muy fuertes entre evangelización y promoción humana $(132 ; 230 ; 796)$. Es la preocupación por el reino y su justicia lo que vincula estrechamente ambas dimensiones: pues el reino interesa a todos, a las personas, a la sociedad, al mundo entero (572); la liberación y salvación que trae alcanza a la persona en su totalidad, abarca e implica todos los ámbitos de la vida humana (465; 467); tiende a transformar las relaciones interpersonales y se realiza a medida que los hombres aprenden a amarse, perdonarse y servirse mutuamente (571). Y todo ello requiere la apertura y conversión a Jesucristo (467), el logro de una nueva vida según Dios de la que surgirá en consecuencia un nuevo tipo de convivencia y relación social (795).

Respecto de la preocupación por el medio ambiente. El Sínodo de 1994/95 reconoce "la conciencia ecológica» como uno de los signos de final del milenio (574) y al medio ambiente y a la ecología como problema prioritario para la Iglesia (782). Constata que cada día crece la mentalidad que busca preservar y defender la tierra, en coincidencia con la mentalidad mapuche, y contrapuesta a la visión mercantilista que la explota y destruye (802). Afirma que desde la perspectiva de una teología de la creación y de la salvación (803), los cristianos no miramos el universo solo como naturaleza, sino que lo entendemos como creación y primer don del amor del Señor por nosotros (801): entonces el hombre es responsable de la historia y de la creación (215), de su liberación (803) y crecimiento hacia su plenitud definitiva (399). Manifiesta la necesidad de formar conciencia, educar, colaborar ante la destrucción progresiva del ambiente natural (838); también la necesidad de propiciar una ética ecológica que considere el destino universal de los bienes de la creación y la promoción de la justicia y la solidaridad (801).

\section{La dignidad humana}

El Concilio se hizo eco del dinamismo de su época que promovió esta dignidad y los derechos del hombre. Valoró dicho dinamismo y creyó poder aportar un fundamento más sólido para el reconocimiento de tal dignidad y de tales derechos ${ }^{18}$.

Ahora bien no siempre es clara en la enseñanza del Vaticano II acerca de la dignidad humana la distinción entre un antropocentrismo de raíces bíblicas y el antropocentrismo prometeico de la modernidad occi-

$18 \quad$ Cf. GS 41 
dental. Lo cierto es que en el tema de la dignidad humana y en el tema de la imagen parece primar un concepto más bien moderno que bíblico, incluso en la interpretación del mismo dato escriturístico. El Concilio parece identificar unilateralmente la dignidad humana con la capacidad de decisión moral de la persona individual: para el Concilio, así como para la modernidad, la racionalidad y la autonomía moral constituyen la piedra angular de dicha dignidad ${ }^{19}$.

Así se entiende esta dignidad más como una capacidad interior y propia del individuo, que como fruto de un reconocimiento intersubjetivo. Esta segunda perspectiva es también considerada por el Vaticano II pero, lamentablemente, la desarrolla menos. Así, lo que ciertamente constituye un original aporte de la reflexión conciliar, quedó subsumido en la comprensión moderna de la dignidad humana.

Lo específico cristiano pareciera ir más bien en la línea de la intersubjetividad. El mismo Concilio ha afirmado con claridad que, desde una comprensión cristiana, la intersubjetividad y la sociabilidad constituyen notas determinantes de lo humano ${ }^{20}$. En este contexto alcanza una nueva comprensión la realidad de la dignidad humana: ella ya no puede consistir en un atributo propio del individuo en sí, sino que surge en el ámbito de las relaciones interpersonales que son constitutivas del ser individual. Así lo enseña Gaudium et Spes cuando afirma que el Evangelio garantiza la dignidad humana puesto que, entre otras razones, «encomienda a todos a la caridad de todos» (GS 41). La caridad es en definitiva el fundamento de la dignidad humana. No hay otra ley más potente, universal y permanente que la del amor, que pueda ser raíz y razón del valor inviolable de todo ser humano (GS 24).

Pareciera ser que el Vaticano II echa mano a fuentes distintas para fundar su discurso antropológico, busca integrar argumentos tanto filosóficos como bíblicos (DH 2), pero da la impresión de que no logra armonizarlos del todo. Más aún, lo propiamente bíblico cristiano pareciera perder fuerza y quedar oscurecido ante una perspectiva más propia de la cultura de la época ${ }^{21}$. Se podrá objetar que para dialogar con el mundo

19 Cf., por ejemplo, DH 1; 2; 11

20 Cf. GS 12; 24; 29; 52; NAE 5; AG 7

21 Confrontar el debate acerca del origen kantiano o cristiano de la noción de la dignidad humana: «El debate se concentra en el papel que la filosofía kantiana ha jugado en la cosmovisión cristiano-católica alrededor de nociones tales como dig- 
el Concilio quiso usar como punto de partida un lenguaje entendible por todos, que pudiera ser acogido con facilidad. Pero a ello habría que doblemente objetar que en esto se depende también de quiénes sean los interlocutores: y pareciera ser que en el caso del Concilio se trata sobre todo del hombre ilustrado, ciudadano del primer mundo.

Los sínodos de la Diócesis de Temuco prolongan la comprensión intersubjetiva de lo humano al promover una clara y prioritaria opción por las comunidades de base. Ella no es solo una opción eclesiológica, sino sobre todo antropológica.

El primer acuerdo del Sínodo de 1968 dice relación con la creación y atención de comunidades cristianas, ya sean territoriales o ambientales (1. 1; cf. 5 .3). La finalidad de las mismas, junto con que los cristianos vuelvan a sentirse como pertenecientes a una misma familia y la Iglesia sea un acontecimiento visible para todos los hombres, es que en ellas pueda vivirse la fraternidad más allá de toda diferencia o distancia (1.2) y que se cultive la caridad fraterna en actividades no solo cultuales (1.9). Se propone que en seno de las comunidades cristianas se practique de la revisión de vida (2.14), se destaque el aspecto comunitario de la liturgia y se promueva la participación de los fieles en ella (3. 2. 5. 17).

En el segundo Sínodo se afirma que las comunidades eclesiales de base responden a la antropología y eclesiología del Vaticano II: el hombre creado a imagen y semejanza de Dios es llamado a participar de la comunión divina no aisladamente sino como pueblo (272), en la Iglesia, Pueblo de Dios y Cuerpo de Cristo, en donde la comunión y participación constituyen una de sus principales características (280). Se recuerda que las comunidades eclesiales de base han constituido en la Diócesis de Temuco uno de los aciertos pastorales más significativos de los últimos tiempos. Se propone crear nuevas comunidades eclesiales de base (304): que formen a sus miembros buscando un mayor protagonismo

nidad humana, derechos personales, universalidad de la paz y la democracia, etc. El debate se divide en dos cuestiones que a veces se confunden: una, si Kant influyó o no en los personalistas cristianos que influyeron y prepararon el camino del Vaticano II al respecto, y dos, si esa influencia fue positiva para el catolicismo, esto es, una evolución conforme a su tradición o un agregado extraño...» (G.J. ZANOTTI, Dignidad humana y derechos de la persona: ¿cristianismo o Kant? A propósito de un debate en "Markets \& Morality", marzo de 2006, http://www.institutoacton.com. ar/articulos/gzanotti/artzanotti19.doc. 
laical (306), que conozcan la realidad que afecta la vida de las familias y personas de su sector (307), que sean escuela y testimonio de comunión fraterna (308). Se desea que dentro de estas comunidades se desarrollen grupos más pequeños, especialmente de carácter ambiental, que permitan a sus miembros un mejor cultivo de la fe, relaciones interpersonales más profundas y fraternas que faciliten la acción testimonial y una más efectiva labor de orden temporal (319).

También la comprensión intersubjetiva de la dignidad humana asoma en el reconocimiento y promoción del papel de la mujer que ambos sínodos impulsan. El primero llama a que los cristianos luchen incesantemente porque la mujer ocupe el lugar que Cristo le da en el Evangelio y se eliminen los prejuicios que aún subsisten frente a ella (4. 3), ya en la sociedad (4. 4), ya en la Iglesia (4. 5). El segundo dedica a la mujer amplias reflexiones: reconoce su dignidad, valor y vocación ya presentes en el relato bíblico de la creación (624-627), pero más aún en el misterio de la encarnación y en la historia de Jesucristo (628-631); así como en la figura de la Virgen María (632-635). Habla de la situación de pobreza (638639), inequidad laboral (640-641; 653), discriminación y desvalorización que sufre la mujer tanto en la sociedad (647-649) como en la misma Iglesia $(647 ; 650-651)$. Todo ello a pesar de los importantes roles que cumple la mujer (642-646) y del protagonismo (647) y capacidad de organización (652) cada vez mayores que va alcanzando. Propone escuchar a las mujeres y alentarlas a aportar su genio femenino para construir una sociedad más humana y una Iglesia más íntegra (655). Hacer del tema mujer una línea de acción pastoral (656), reconocerla como miembro activo de la Iglesia (657), con participación en la toma de decisiones (659) y con mayor posibilidad de asumir tareas y servicios ministeriales (660).

\section{NO LOGRA SUPERAR LOS TEMORES DE SIEMPRE}

Al elaborar su antropología teológica

El Concilio se propone enlazar con su fuente divina aquellos valores que hoy gozan de la más alta estima ${ }^{22} \mathrm{y}$, así, fundarlos más sólidamente ${ }^{23}$. Con ello, en lo práctico, se quiso superar la falsa encrucijada -o Dios o

$\begin{array}{ll}22 & \text { Cf. GS } 11 \\ 23 & \text { Cf. GS } 40-45\end{array}$ 
el hombre- a la que condujo a la cultura occidental no solo cierta filosofía moderna, sino también la misma Iglesia con su postura más bien defensiva ante la misma.

En Tertio Millennio Adveniente el papa Juan Pablo II resumió la teología conciliar en estos términos: el mensaje conciliar presenta a Dios en su señorio absoluto sobre todas las cosas, y también como garante de la auténtica autonomía de las realidades temporales ${ }^{24}$.

Con esta afirmación el Papa señaló, con delicada precisión, lo que es la gran apuesta del Concilio -lo divino como fundamento de la autonomía de lo mundano-, y, al mismo tiempo, su gran límite: no haber sabido unir conceptualmente ambas realidades. El «atque etiam» (y también) de la frase del Papa, que en ello dice bien los límites de la teología conciliar, parece mantener una distinción que no deja de ser distancia entre el reconocimiento de Dios y la valoración de la autonomía del mundo. El «y también» no deja de sugerir que se trata de dos cosas distintas y distantes el «señorío absoluto de Dios» y la «autonomía de las realidades temporales», quedándose entonces solo a nivel de no contraponer ambas verdades, cuando el gran paso hacia el cual pudo encaminarse el Concilio era más bien unir ambas y hacer depender lo uno de lo otro. Lo cierto es que la unidad y la integración de ambas realidades no quedan bien expresadas con el adverbio «etiam» que acompaña y transforma el «ilativo» en «disyuntivo».

El Concilio no «soltó amarras», mantuvo un cierto recelo ante la autonomía humana: una y otra vez señaló sus límites y peligros ${ }^{25}$. Por ello no supo, ni pudo, vincular positivamente el reconocimiento de Dios

24 TMA 20: Conciliari in nuntio exhibetur Deus sua in plenissima rerum omnium dominatione, atque etiam veluti temporalium rerum libertatis custos.

25 En el número 36 de Gaudium et Spes hay una clara manifestación del valor de la autonomía de las cosas creadas y de que Dios creador es el garante de la misma, pero también una clara advertencia: «... si autonomía de lo temporal quiere decir que la realidad creada es independiente de Dios y que los hombres pueden usarla sin referencia al Creador, no hay creyente alguno a quien se le oculte la falsedad envuelta en tales palabras. La criatura sin el Creador desaparece». Lo mismo sucede en Gaudium et Spes número 41. En el número 59 de la Constitución Pastoral, ahora hablando de la cultura y de las ciencias, el tono parece distinto: se afirma sin recortes su legítima autonomía, salvados el orden moral y la común utilidad. 
y esta autonomía ${ }^{26}$. Y entonces no supo hacer una clara apuesta por el valor autónomo del actuar humano: hizo de la conciencia de los peligros un freno. Y esto va a costar caro: rápidamente la autonomía del hombre y del mundo se entenderán como atentatorias respecto de los derechos de Dios sobre todo lo creado y la amenaza del secularismo pauteará la relación Iglesia-mundo. La no integración derivará prontamente en una oposición que revivirá los peores pasajes de la teología preconciliar.

Para superar dicho freno se hace necesario ubicar decididamente la actuación humana en el contexto mayor del designio divino de hacer participar toda la realidad de su vida divina: el mundo viene de Dios y va hacia Dios y, entonces, la historia de la creación se da al interior de una economía mayor que es la economía del amor, la economía de la gracia, la economía de la divinización: de la comunión del hombre con $\operatorname{Dios}^{27}$. También se hace necesaria una renovada comprensión del actuar de Dios en el mundo: Dios legitima la autonomía de lo creado, está presente y actúa en el mundo sin por ello anular el dinamismo propio de la criatura, sino que, por el contrario, alienta este dinamismo y lo lleva a su auténtico cumplimiento.

$\mathrm{Al}$ valorar la libertad humana

El número 17 de Gaudium et Spes afirma que la libertad «es signo eminente de la imagen divina en el hombre» y que la orientación del hombre a Dios no suprime la libertad humana, sino que por el contrario, es lo que le da a esa libertad su verdadero sentido: «Dios ha querido dejar al hombre en manos de su propia decisión para que así busque espontáneamente a su Creador y, adhiriéndose libremente a este, alcance la plena y bienaventurada perfección». Asimismo, reconoce el valor principal de actuar en conciencia, como expresión de la libertad que a todos corresponde debido a su dignidad de personas: «la dignidad humana requiere,

26 Aunque a algún autor parezca lo contrario: cf. A. TORRES QUEIRUGA, «El Vaticano II y la teología”, Revista internacional de Teología Concilium 312 (2005) 27(467) 40(480). Afirma este autor que «el Concilio no pone límites a la legitimidad de autonomía que reclaman imperiosamente los hombres de nuestro tiempo, lo que hace, desde el punto de vista religioso, es pedir su justa integración dialéctica con el proyecto del creador y dar a entender que es precisamente desde este proyecto que adquiere mayor peso dicha autonomía».

27 Lo encontramos insinuado en AA 7. 
por tanto, que el hombre actúe según su conciencia y libre elección, es decir, movido e inducido por convicción interna personal y no bajo la presión de un ciego impulso interior o de la mera coacción externa ${ }^{28}$; lo que se hace mayormente estimable en relación a la libertad religiosa ${ }^{29}$.

Gaudium et Spes habló del sagrario de la conciencia (cf. GS 16) y Dignitatis Humanae remite permanentemente a ella como condición básica de la libertad religiosa, afirmando que ha de ser respetada incluso cuando se halle en el error (cf. DH 11).

El primer Sínodo de la Iglesia diocesana de Temuco parece recoger una primera lectura del novedoso decreto sobre la libertad religiosa que entregó el Vaticano II, al promover el respeto por la respuesta que cada cual pueda dar al anuncio de Jesucristo. Se llama a los laicos a que en el ejercicio de su apostolado no guarden para sí mismos la riqueza que es conocer y amar a Cristo, pero que no por ello impongan a otros lo que es un bien para ellos mismos, sino que «...propongan, más bien, al Señor, aguardando la respuesta libre y voluntaria de los hombres» (8. 4).

El segundo Sínodo, también fundado en el Concilio, pone un acento levemente distinto. Señala en el número 461, en el contexto amplio de la reflexión acerca de la acción misionera, que el anuncio de la persona y el mensaje de Jesucristo es una propuesta hecha a la libertad del hombre, un llamado que respeta la conciencia humana; pero también afirma el carácter absoluto de la persona y mensaje de Jesús y que sin la revelación plena ofrecida en Jesucristo, la humanidad y sus búsquedas permanecen en la penumbra de lo relativo. Así también, en el número 848, al hablar de la evangelización del pueblo mapuche, afirma que en el anuncio de Jesucristo no se trata de un proselitismo exclusivista y condenatorio que arrasa con los valores de un pueblo, sino que más bien se trata de una propuesta hecha a la libertad del hombre, y remite a Redemptoris Missio 6, párrafo que afirma la singularidad de Cristo y su significado absoluto $^{30}$.

De hecho Dignitatis Humanae 2 habla del derecho a la libertad religiosa pero también de la obligación moral de buscar la verdad: todos los

\footnotetext{
28 Lo mismo en GS 41.

29 Cf. DH 2

30 Lo cierto es que son los números 7 y 8 los que desarrollan más ampliamente el tema de la libertad.
} 
hombres, conforme a su dignidad, por ser personas, es decir, dotados de razón y de voluntad libre, y, por tanto, enaltecidos por la responsabilidad personal, tienen la obligación moral de buscar la verdad, sobre todo la que se refiere a la religión. Están obligados, asimismo, a adherirse a la verdad conocida y a ordenar toda su vida según las exigencias de la verdad. Ambos aspectos, el derecho a la libertad y el deber de la verdad, no se pueden disociar y en su conjunto dan su correcto sentido al concepto de libertad en general y de libertad religiosa en particular ${ }^{31}$.

Lo anterior es ciertamente correcto, y entonces es necesario admitir que si bien la verdad es algo que se nos ha dado totalmente en Cristo, es también algo que todos necesitamos descubrir en toda la amplitud de su significación. Lo importante es saber cómo acompañar ese proceso de descubrimiento sin violentar las conciencias y sin que el sentido de la verdad lo inhiba. Es el riesgo de la libertad cuya equivocidad no puede paralizar su ejercicio. El Concilio manifestó una gran sensibilidad para con este riesgoso equilibrio entre verdad y libertad, equilibrio no siempre apreciado y respetado a lo largo del pos concilio que llevamos.

\section{DESARROLLA POCO SU PROPIA PERSPECTIVA}

El sello cristológico - trinitario

El Concilio se asoma, aunque muy tímidamente, a una comprensión trinitaria de la problemática antropológica. Recordando las palabras de la oración sacerdotal de Jesús se afirma en el número 24 de Gaudium et Spes que es posible entender una cierta semejanza entre la unión de las personas divinas y la unión de los hijos de Dios en la verdad y en la caridad. Esta indicación es de máxima importancia pero lamentablemente no es desarrollada por el Concilio. La timidez trinitaria del Vaticano II en relación a lo antropológico, que contrasta con su amplia referencia eclesiológica, recortó la visión cristiana del hombre.

31 El papa Benedicto XVI, en el discurso anteriormente reseñado, afirma que la tolerancia religiosa, acogida y promovida por el Concilio, no tiene que ver con una relativización de la verdad y por eso no obsta la acción evangelizadora de la Iglesia. Es más bien una necesidad que deriva de la convivencia humana y debe ser entendida como una consecuencia intrínseca de la verdad, que no puede ser impuesta desde fuera sino que el hombre debe hacer suya mediante un proceso de convicción. 
Lo mismo es necesario decir respecto de la referencia cristológica. El Vaticano II manifiesta una notable insuficiencia cristológica: una escasa referencia al Cristo histórico y a la centralidad del reino.

Como sabemos el tema de la imagen centra la comprensión del hombre que nos ofrece Gaudium et Spes y está también presente en otros documentos del Vaticano II $^{32}$. Es posible reconocer a la luz del conjunto de los textos que la expresión pretende indicar algo del hombre en cuanto este se encuentra totalmente referido a Dios, a los otros hombres y a la naturaleza. Señala en el hombre unas capacidades y, al mismo tiempo, una orientación. El número doce de Gaudium et Spes marca la pauta del sentido que tiene la expresión dentro de la antropología conciliar: creado a imagen de Dios el hombre tiene la capacidad de conocer y amar a su creador, de gobernar y usar la creación para la gloria de Dios y de relacionarse con los demás.

Ahora bien, el hombre «imagen de Dios» no deja de ser un tema veterotestamentario. A partir de Col 1, 15 el Concilio cristianiza el concepto: habla de Cristo como imagen de Dios invisible, primogénito de toda criatura ${ }^{33} y$, por tanto, fuente y corona de la verdad sobre el hombre ${ }^{34}$ : nosotros necesitamos conformarnos con la imagen del Hijo, para que sea Él el primogénito entre muchos hermanos (Rom 8, 29), y nosotros alcancemos en Él la filiación divina. Pero se trata hasta aquí del Resucitado.

El número ocho de Lumen Gentium da un paso más cuando afirma que la Iglesia reconoce en los pobres y en los que sufren la imagen de su Fundador pobre y paciente, se esfuerza en aliviar sus necesidades y pretende servir en ellos a Cristo. Es de la mayor importancia esta afirmación de la Constitución sobre la Iglesia: el recurso a la historia de Jesús amplía la comprensión del ser imagen de Cristo y del ser imagen de la imagen que es lo propio del hombre. El ser imagen no se identifica ahora con capacidades, sino más bien con carencias: pobreza y sufrimiento paciente. Es esta otra antropología, más bíblica y menos moderna.

Con ello se nos abre a una nueva comprensión de nosotros mismos: Cristo, en su ministerio mesiánico y en su estilo de vida pobre y obedien-

\footnotetext{
32 Por ejemplo, NAE 5; AG 7; AA 8

33 Cf. LG 2; 7; GS 10; 22

34 Cf. GS 22
} 
te, nos recuerda que el hombre es un ser ontológicamente menesteroso ${ }^{35}$ : necesitado de complementariedad, de ser completado desde fuera de sí mismo. Signo de ello es también la trágica condición en la que se ubica el hombre cuando se repliega sobre sí mismo: queda profundamente dividido, inclinado al mal, impulsado a cerrarse a la comunicación y a la comunión, ahogado en una propia autosuficiencia orgullosa ${ }^{36}$.

Al Concilio le faltó reflexionar más su antropología a partir de la vida histórica de Jesús. No podía hacerlo. Los estudios cristológicos recién alcanzaban su madurez. Hay sí alguna intuición al respecto: es claro que su comprensión del hombre se centra en Jesucristo. Y, hay también referencias al ministerio histórico de Jesús, aunque pocas y dispersas ${ }^{37}$. Lo importante es que se trata de una línea de trabajo que la teología posconciliar ha profundizado pero que a mi entender no se ha hecho todavía decisivamente presente en la comprensión antropológica de nuestras comunidades eclesiales.

Esta línea de trabajo ha derivado especialmente en Latinoamérica en la señera opción por los pobres. De ello dan cuenta los sínodos de Temuco.

En el primer Sínodo es claro que la promoción humana se perfila en la perspectiva de los pobres y débiles: se expresa una permanente preocupación por los menos favorecidos, se invita a los cristianos a actuar de tal modo que sea posible para ellos «surgir y acceder a la cultura y al bienestar», al tiempo que se insta a estos menos favorecidos a que «luchen por mejorar su condición con firmeza» (4.10). Especial preocupación se manifiesta por los campesinos que inmigran hacia los centros urbanos y permanecen en situación de marginación (3. 6; 8. 13 y 14).

El segundo Sínodo afirma con claridad que la opción por los pobres se halla bien fundada en la persona y ministerio de Jesucristo: se trata de una opción evangélica y preferencial (804-805). La pobreza y los pobres son preocupación prioritaria para la Iglesia (782) y debieran también serlo para la sociedad (808). Manifiesta especial preocupación por el

\footnotetext{
35 La afirmación la recojo de un trabajo de Pedro Morandé Court: La Gaudium et Spes y la misión de la Iglesia, frente a los desafíos antropológicos de la época actual, $26 \mathrm{de}$ enero de 1996, en http://www.multimedios.org/docs/d000196/

36 Cf. GS 12 y 13

37 Por ejemplo en LG 5; 6; 8; 19; 22: 32; 40; 58; GS 22; 32; 38; DH 1
} 
amplio margen de pobreza de la Región $(14 ; 19 ; 20 ; 825 ; 865)$ y por el deterioro del nivel de vida de los pobres $(809 ; 952)$. Dice que la preocupación por los pobres consiste, a la vez, en atenderlos preferencialmente (74; 749; 768; 778; 789; 794), y promoverlos socialmente (813). Pero para ello es necesario aprender a ver la realidad desde los pobres (812). Más aún, no se trata de atender a los pobres desde fuera, desde lejos, sino de estar presente entre los más pobres $(101 ; 174 ; 748)$, dando en medio de ellos testimonio de pobreza, de vida austera y sencilla, compartiendo solidariamente su suerte (103), asumiendo la pobreza como estilo de vida personal y en las estructuras eclesiales (804).

\section{ENTONCES SU RIQUEZA ES PRONTAMENTE OLVIDADA}

La valoración de la historia

Estamos aquí ante un núcleo central y característico de la teología del Concilio Vaticano II: la historia no es un accidente o un hecho extraño, sino una realidad constitutiva de la salvación esperada y anunciada por los cristianos.

Esta valoración, que tiene una razón eminentemente teológica -la comprensión unitaria de los misterios de la creación y la redención ${ }^{38}$-, es perceptible en la intencionalidad pastoral del Vaticano II, que señala el deseo de unir la verdad del Evangelio a las exigencias de la historia, que fue, precisamente, el horizonte en el que el papa Juan XXIII quiso ubicar el Concilio ${ }^{39}$. Es también perceptible en el reconocimiento teológico de la historia que se esconde detrás de la expresión evangélica «signos de los tiempos» ${ }^{40}$ que comporta un reconocimiento positivo de la historia, como auténtico lugar en el que se percibe la presencia inminente del Reino.

38 Cf. GS 41

39 Esto quedó de manifiesto en dos intervenciones suyas previas a las deliberaciones conciliares: la Constitución Apostólica Humanae Salutis, por la que convocó el Concilio; y su radiomensaje del 11 de septiembre de 1962 La gran espera del Concilio, que difundió poco antes de iniciarse la asamblea. El texto de ambos documentos lo encontramos en Acta et Documenta Concilio Oecumenico Vaticano II Apparando, Cura et Studio Secretariae Generalis Concilii Oecumenici Vaticani II, 1960-1968, Serie II, Vol. I, 132-135, el primero y 348-355, el segundo). 
No cabe duda que, desde la celebración del Concilio hasta acá, los signos de los tiempos cambiaron y que esto ha exigido una reflexión teológico-pastoral nueva y más profunda, que interprete tales signos a la luz del evangelio: fue lo que propuso la Segunda Asamblea Extraordinaria del Sínodo de los Obispos, convocada en 1985 para celebrar, verificar y promover el Concilio ${ }^{41}$. Ahora bien, esto fue precisamente lo que hizo el Vaticano II y fue lo que en definitiva entregó como herencia a la Iglesia: saber y querer leer con aprecio los signos de la propia época para descubrir en ellos la voz de Dios para la Iglesia y el mundo. En ello se logró la superación del enclaustramiento defensivo como estilo pastoral y se miró al mundo con realismo y benevolencia, siendo capaz de discernir en él posibilidades de vida nueva, escondidas y reconocibles en su propio dinamismo histórico.

A partir de esta valoración se reconocerá la profunda coherencia que hay entre el evangelio creído y proclamado y el deseo del hombre expresado de múltiples formas en su actuar histórico ${ }^{42}$. También se reconocerá la legítima autonomía del hombre, de la sociedad, de la cultura y de la ciencia, pues ella responde a la voluntad de creador $^{43}$. El mismo actuar humano será reconocido y apreciado como insustituible en el desarrollo de las potencialidades naturales ${ }^{44}$. Y no solo eso: sino que además se le reconocerá un papel no menor en el advenimiento del reino futuro ${ }^{45}$.

En coherencia con esta valoración los sínodos de Temuco hablan de la importancia de reconocer, respetar y aprovechar las riquezas de la diversidad cultural. El primero manifiesta una incipiente sensibilidad para con la diversidad de comunidades y ambientes que se dan en el seno de la sociedad y de la Iglesia ${ }^{46}$. El segundo, constata la condición

41 El texto de su Relatio finalis lo encontramos en L'Osservatore Romano, 22 de diciembre de 1985, 779/11 - 782/14. La afirmación acerca de la existencia de nuevos signos de los tiempos la encontramos tres veces en esta Relatio Finalis: II.A.1 (pág. 12); II.D.1 (pág. 13); II.D.7 (pág. 14).

42 Cf. GS 10; 21; 41; AG 8-9

43 Cf. GS 36; 59

44 Cf. GS 53

45 Cf. GS 39

46 Se pide que para la preparación al matrimonio se implementen «charlas, adaptadas, dentro de lo posible, a los diversos ambientes» (3.15) y se exhorta a que «la celebración eucarística pueda adaptarse en su rito a las circunstancias propias de las diversas comunidades y ambientes» (3.18). 
pluriétnica y pluricultural de la Novena Región y manifiesta la necesidad de adaptarse a ella $(393 ; 479)$. Habla de la existencia de diversas culturas que se entrecruzan en la Región de La Araucanía: moderna (876), urbana (127), mapuche $(25 ; 127 ; 194 ; 664 ; 853 ; 861)$, campesina (127), juvenil (701), de los pobres (952). Afirma que hoy por hoy se valora más, aunque aún no de modo suficiente (869) la pluriculturalidad de nuestras sociedades $(102 ; 127 ; 353 ; 393 ; 479 ; 869)$.

$Y$ tienen especialmente en cuenta la existencia, cultura y riquezas del pueblo mapuche. El primer Sínodo habla poco de él, aunque sí afirma el deseo de darle una atención preferente y de acuerdo a sus necesidades e intereses $(4.13)^{47}$. El segundo Sínodo le dedica amplias reflexiones: habla de la necesidad de valorar sus riquezas $(179 ; 861)$, a saber, sus tradiciones, idioma y valores, pues ellas son expresión de la multiforme manifestación de la única semejanza que todos los hombres poseen con el creador, como dijera el papa Juan Pablo II, en abril de 1987, con ocasión de su vista a Temuco (849) ${ }^{48}$. Recuerda que la Iglesia, sin dejar de anunciar la persona y verdad de Jesucristo (845), desea conservar todo cuanto es noble, verdadero y bueno en las religiones y culturas de los pueblos con los que se encuentra (850). Por ello, al tiempo que reconoce lo importante que ha sido la evangelización del pueblo mapuche $(25,202)$, propone continuar los esfuerzos pastorales, en la línea de una mejor inculturación de la fe entre ellos (850), especialmente en la liturgia (874) y en la catequesis (877), que redunde en una evangelización más viva (880). A la par, desea una mayor profundidad en el trabajo de promoción humana y educación de los mapuches (882). Considera también importante la tarea de ayudar a recuperar su identidad, en armonía, diálogo y apertura con la cultura moderna (876), y la preocupación por informar y difundir la cultura y costumbres mapuches a la sociedad en

47 En la Introducción se habla de promover una «Comisión Pastoral Rural e Indígena» (Introducción, 3. 6).

48 Lo cierto es que se trata de uno de los pueblos precolombinos más vitales existentes en Chile (839), cuya sociedad y cultura forjada a lo largo del tiempo se caracteriza por un particular esquema social, por una propia percepción del mundo, del sentido de la vida, de la muerte, de la convivencia. En su seno se articulan tradiciones, mitos, costumbres y ritos religiosos que responden a sus interrogantes más fundamentales y que constituyen parte esencial de su cultura (841). Como sucede con los pueblos y culturas antiguos destaca en el pueblo mapuche su fuerte sentido de lo sagrado, el sentido de familia, el amor a los hijos, el respeto por los ancianos, los vínculos comunitarios con los antepasados, su simbolismo y gusto por lo ritual (844). 
su conjunto (879). Y en esto la misma Iglesia tiene una tarea en el seno de sus propias comunidades (194), así como de cara a la sociedad en su conjunto (879).

Ahora bien, este reconocimiento y valoración de la historia -que en el caso de los sínodos de Temuco vemos presente en la atención que prestan a la diversidad cultural y a la existencia del pueblo mapuche-, podría traer consigo importantes consecuencias para el ser y quehacer evangelizador de la Iglesia: significar, por ejemplo, un enriquecimiento en la penetración de la verdad a ella confiada y también en la comprensión de sí misma. Esto lo enseña el Concilio cuando afirma que es necesario atender a «las múltiples voces de nuestro tiempo y valorarlas a la luz de la palabra divina, a fin de que la Verdad revelada pueda ser mejor percibida, mejor entendida y expresada en forma más adecuada y al manifestar que la Iglesia puede enriquecerse, y de hecho se enriquece también, con la evolución de la vida social, no porque le falte en la constitución que Cristo le dio elemento alguno, sino para conocer con mayor profundidad esta misma constitución, para expresarla de forma más perfecta y para adaptarla con mayor acierto a nuestros tiempos» ${ }^{49}$.

El Concilio lo reconoce, pero no hace de ello un tema mayor. En esto el Vaticano II quedó a medio camino, entreabrió la puerta, pero no supo dar el paso decisivo. De hecho rápidamente se silencia tal comprensión. Así por ejemplo el Segundo Sínodo de Temuco expresa una convincente atención a los nuevos signos de los tiempos ${ }^{50}$, pero entendiéndolos más como desafíos a la acción evangelizadora de la Iglesia, que como aportes al enriquecimiento de la misma Iglesia o a su comprensión de la verdad revelada de la que es depositaria. Se corresponde con esto que el mismo diálogo con la cultura tenga más bien el carácter de un monólogo, incluso cuando se asume la perspectiva de la inculturación del Evangelio.

49 GS 44. Subrayo lo que me parece relevante. Ambas afirmaciones entrañan una «sana relativización» en la penetración de la verdad y también en la comprensión de la Iglesia, posible y necesaria, y también correspondiente a todo tiempo anterior a la parusía de Cristo.

50 La nueva cultura (575-578), las comunicaciones sociales (579-580), el dinamismo económico mundial unipolar (581-582), la situación de la familia nuclear (585), la inserción y protagonismo de las mujeres en la sociedad (583-584), el pluralismo ideológico 586-590) y la creciente conciencia ecológica. 
El Segundo Sínodo habla ampliamente de inculturación. La entiende como gran desafío y exigencia del mundo pluricultural en el que vivimos $(102 ; 222)$ y como estilo pastoral necesario para llegar a la raíz de la cultura, al estilo de vida común que poseen los hombres (225). Habla de ella como del esfuerzo de encarnar el Evangelio en las diversas culturas $y$, al hacerlo, no destruir, sino que más bien conservar, consolidar y fortalecer sus valores, y más aún, transmitirlos y devolverlos mejor logrados a las mismas culturas; asumiendo de esta manera lo que hay de bueno en ellas y renovándolas desde dentro $(851 ; 850)$. Una evangelización así entendida hace crecer las semillas esparcidas por el Verbo de Dios, que antes de hacerse carne para salvarlo todo y recapitularlo todo en El, estaba en el mundo como luz verdadera que ilumina a todo hombre (853).

Pero poco dice de lo que la cultura y las diversas culturas pueden aportar como riqueza a la misma Iglesia y a su acción evangelizadora. Lo cierto es que el Sínodo no logra apropiarse de la orientación y riqueza de contenidos del capítulo sobre el sano fomento del progreso cultural de la Constitución Gaudium et Spes. El diálogo parece más bien un monólogo y la inculturación parece más un viaje de ida y no de regreso, como si hubiera un solo poseedor de la verdad y la poseyera ya de manera absoluta. Es cierto que puede parecer a más de alguien excesiva la inocencia y el optimismo que profesó el Concilio sobre el progreso cultural, pero no se puede silenciar la riqueza de su intuición respecto del aporte de la cultura al desarrollo humano y al enriquecimiento de la misma Iglesia ${ }^{51}$.

La íntima unión entre historia humana e historia de salvación

Desde la radical referencia a Cristo y al mundo el Concilio planteó perspectivas antropológicas nuevas, pero lamentablemente no profundizó en ellas, ni derivó claras consecuencias de las mismas. Entonces la novedad se perdió fácilmente, pronto se puso el acento en aquello que se quiso equilibrar en el Concilio porque estaba sobrevalorado y, entonces, desequilibrado: la distancia y hasta contradicción entre el Evangelio y la historia humana.

Un ejemplo de esto es la comprensión de la unidad de la historia humana y de la historia de la salvación bajo el único señorío del Dios

51 Cf. GS 58 
creador y salvador ${ }^{52}$, manifestado en la presencia de Cristo -clave, centro y fin de toda la historia humana ${ }^{53}$ - y en la acción del Espíritu que guía el curso de los tiempos ${ }^{54}$. Con la afirmación de este señorío, que lamentablemente solo se enuncia y no se desarrolla, se corresponde la intuición de la existencia de una verdadera kénosis (vaciamiento) divina, de un verdadero ocultamiento de Dios, que hace posible el ejercicio de la libertad humana. Un Dios que humaniza desde dentro y no que irrumpe desde fuera. Un Dios que da espacio al actuar humano. Una acción divina que no sustituye la libertad y el obrar humanos, sino que los sustenta y potencia ${ }^{55}$. Un Dios que por ser, a la vez, trascendente e inmanente al mundo, sostiene y alienta el dinamismo de la propia creatura.

Halla su asiento en esta intuición del Concilio la reflexión teológico pastoral de los sínodos de Temuco que, en clara sintonía con el Vaticano II, promueven decididamente la participación y el protagonismo laical. El primer Sínodo habla a los laicos de su responsabilidad, de sus derechos y deberes en el seno de la misma Iglesia, de cara a la tarea evangelizadora y de cara a su actuación en el mundo: les invita a reconocer su rol, propio e insustituible en el cumplimiento de la misión total de la Iglesia (8.1), a tomar conciencia de su propio sacerdocio real (8.2) y de ser constructores del mundo bajo su propia responsabilidad (cf. 8.5.6). En el segundo Sínodo la reflexión sobre los fieles laicos hunde sus raíces en las mejores intuiciones de Lumen Gentium y Apostolicam Actuositatem: la Iglesia como pueblo de Dios y los laicos como partícipes por el bautismo del ministerio sacerdotal, profético y real de Cristo. El magisterio pontificio y episcopal posvaticano se hace también fuente de la comprensión del papel evangelizador específico del laico que el Sínodo promueve: su carácter secular, su aptitud para evangelizar el medio social y construir la historia. Por eso se insistirá en la necesidad de una formación integral del laicado que lo capacite para ser protagonista de la transformación de los ambientes socioculturales a la luz del Evangelio y la Doctrina Social de la Iglesia (269).

El esfuerzo integrador que caracteriza la teología conciliar quedó prontamente olvidado. Se volverá a insistir más bien en la distinción

52 GS 41.

53 GS 10; cf. 45.

54 PO 22, 3; GS 11, 1; 26, 4; 41, 1; 22, 4; 37, 4.

55 En este sentido podemos leer las afirmaciones del número 34 de Gaudium et Spes. 
y en la dualidad entre historia humana e historia de salvación. Así, por ejemplo, en la Segunda Asamblea General Extraordinaria del Sínodo de los obispos celebrada en 1985, que advierte ante el hecho que muchas veces se ha dado una lectura parcial y selectiva del Vaticano II que no distingue entre la apertura legítima del Concilio hacia el mundo y la aceptación de la mentalidad y escala de valores del mundo secularizado.

En ello late una comprensión que pone distancia entre el mundo y la Iglesia. Lo cierto es que prácticamente se parte de una valoración más bien negativa del mundo: entre los nuevos signos de los tiempos se destaca el secularismo; $y$, si bien se aceptan y defienden fuertemente todos los valores verdaderamente humanos, se señala que deben ser purificados y elevados por la gracia. Desde acá se comprende la afirmación de la necesidad de explicar a la luz del misterio pascual la relación entre la historia humana y la historia de la salvación (II.D.2), y, en consecuencia, la misión misma de la Iglesia: ella poco o nada tiene que recibir del mundo; la relación para con él solo puede rotularse bajo el signo de la acción misionera. Es lo que se pondrá de manifiesto de manera superlativa en el programa de Nueva Evangelización que el papa Juan Pablo II propondrá para la Iglesia latinoamericana y del Caribe.

Tal comprensión se hará presente en el segundo Sínodo de Temuco y más todavía en la Asamblea Postsinodal. Sin embargo, en esta última, y de la mano del deseo de querer escuchar la voz de Dios en los acontecimientos de la historia, en la cultura y en la vida de las personas, asoman perspectivas que pudieran ayudarnos a recuperar una intuición básica del Concilio: a saber que la historia y el mundo tienen mucho que enseñarnos. Que desde ellos se puede penetrar más en la verdad que se nos ha confiado, a la que servimos, no como dueños absolutos, sino siempre desde la delicadeza y el gozo de quien se sabe deudor de la permanente novedad del Evangelio, que siempre sorprende y desinstala.

\section{EL APORTE DE LA ASAMBLEA POSTSINODAL DE 2006}

Curiosamente la Asamblea postsinodal de 2006 señala tres situaciones diversas y, en algún sentido, hasta contradictorias entre sí, respecto de la antropología del Vaticano II y también respecto a cómo ella ha sido recepcionada por la Iglesia diocesana de Temuco en sus dos sínodos posvaticanos hasta ahora celebrados. 
En primer lugar, se da en la Asamblea una situación de continuidad en fidelidad, respecto del Concilio, pero de quiebre, respecto de la reflexión teológico-pastoral de los sínodos, pues la Asamblea recupera, en la línea del Vaticano II, la comprensión teológica del concepto «signos de los tiempos». Manifiesta una gran sensibilidad para con ellos (4; 14; $16 ; 39 ; 44 ; 45 ; 53 ; 80 \mathrm{c} ; 179)$ y los hace referente fundamental para la comprensión misma del misterio cristiano: los cristianos y la Iglesia no somos ajenos a una cultura en la que priman el sentido de la experiencia y de la relación; ella nos desafía pastoralmente y, todavía más, es de valorar el hecho de que, haciendo eco de esta nueva cultura, surjan en la misma Iglesia nuevas formas de espiritualidad, que son ciertamente una nueva manifestación del misterio de la encarnación $(23 ; 48)$.

En segundo lugar, en la Asamblea se da una situación de ruptura e involución respecto de la antropología conciliar, y también de la de los sínodos diocesanos, pues parece perderse en ella el sentido de lo prioritario que es para la Iglesia salir de sí misma y servir al mundo: el tono de su reflexión parece ser el de una Iglesia más centrada en sí misma, en su forma de desenvolverse de cara al mundo, y menos preocupada del mismo mundo. Esto quedó de manifiesto ya en la temática misma que se propuso reflexionar en la Asamblea: ella se centró en la necesidad del testimonio de vida de una Iglesia-comunidad, en la acogida a cada persona, en la formación, en la catequesis, en la liturgia y en la misión (n. 60). Es significativo que queriendo redescubrir la vigencia de las conclusiones del II Sínodo y responder a los desafíos de los signos de los tiempos la Asamblea Postsinodal omita la quinta parte del Sínodo de 1994/95: Iglesia en el mundo, es decir la mirada sobre el mundo y la propia región en aspectos tan centrales como los allí tratados. Qué lejos estamos aquí de lo señalado en uno de los acuerdos del primer Sínodo, el del año 1968, en el que se pedía que «los laicos, que en el presínodo tomamos conciencia de ser "Iglesia", tomemos ahora conciencia, en el postsínodo, de ser "constructores del mundo", bajo nuestra propia responsabilidad» (8.5).

En tercer lugar, se da una situación de profundización creativa respecto del Concilio, ya insinuada en los sínodos, pues la Asamblea propone orientaciones antropológicas desde la recuperación del Jesús histórico y su ministerio mesiánico. Al hablarnos de la necesidad de un nuevo modo de ejercer la autoridad y el liderazgo (24) invita a recuperar el liderazgo 
de Jesús -diferente del que ofrece el mundo-, liderazgo de servicio, en el que el líder es un siervo vulnerable, que necesita a los otros, no menos que lo que los otros le necesitan a él. Un liderazgo no modelado sobre los juegos de poder, sino sobre Jesús, líder-siervo, venido a dar la vida por la salvación de muchos $(24 ; 49 ; 81 ; 103)$. Se trata de una intuición, que si se asume y profundiza, podría ser de mucho provecho para la Iglesia misma y para su diálogo con el mundo.

\section{CONCLUSIÓN}

Hemos querido mirar el Concilio desde la recepción de su antropología en la reflexión teológico-pastoral de una Iglesia diocesana. Ello nos ha permitido redescubrir sus riquezas al tiempo que reconocer sus ambigüedades y lagunas.

La discusión antropológica permanece abierta. El Concilio no la ha cerrado, lo que ha hecho ha sido dar un paso que equilibra la discusión antropológica en el seno de la misma Iglesia y de cara al mundo. Es necesario recuperar este equilibrio. Pero para hacerlo hay que ir con el Concilio más allá del Concilio: recuperar su espíritu y profundizar sus intuiciones; superar sus timideces y caminar con más decisión por los senderos que intentó recorrer.

No siempre ha sido así a lo largo de los años de postconcilio que llevamos. Hemos pasado de una época más antropológica, en la que el hombre y el mundo han centrado la atención, a una más eclesiológica, en la que la Iglesia y su misión han acaparado las miradas. Hemos pasado de una época en la que se ha reconocido una profunda unidad entre los anhelos del mundo y el Evangelio anunciado, a una en la que se ha puesto distancia y hasta contraposición entre lo uno y lo otro.

Para recuperar el espíritu del Concilio y profundizar en sus intuiciones renovadoras será necesario hacer de la cristología una clave maestra. Lo fue ya para el mismo Concilio, que afirma precisamente que «el misterio del hombre solo se esclarece en el misterio del Verbo encarnado" (GS 22). Pero la cristología del Concilio es incipiente. Pues se ubica solo al comienzo de una época que ha dado mucho fruto en la investigación y recuperación de la figura histórica de Jesús. Y será desde esta recuperación desde la cual se podrán reconocer las intuiciones antropológicas más originales de la visión cristiana del hombre y del mundo. 
Ya en el segundo sínodo y en la asamblea postsinodal el recurso al ministerio público y a la humanidad de Cristo enriqueció la visión antropológica de los mismos. Se trata de una línea de reflexión que puede acarrear grandes aportaciones no solo a nivel de la discusión teológicopastoral de la Iglesia, sino también a nivel de la vivencia de las comunidades cristianas. Y ciertamente, desde allí, se podrá aportar grandemente a los anhelos y búsquedas de los hombres y mujeres de nuestro tiempo. 
Resumen: Este artículo intenta una mirada crítica al Concilio Vaticano II, desde la recepción de su enseñanza antropológica en la reflexión teológico-pastoral de los sínodos de la Diócesis de Temuco. Estos sínodos, celebrados en épocas distintas, y urgidos por diversas situaciones sociales y eclesiales, manifiestan propias acentuaciones, a veces hasta contradictorias, en la comprensión de la antropología conciliar. Es posible postular que estas propias acentuaciones tienen que ver en mucho con lo poco conclusa de la antropología del Vaticano II. De hecho los sínodos en cuestión beben de su riqueza, pero también reflejan sus vacíos y debilidades. Sin embargo, estos mismos sínodos son también testigos de que el Concilio sembró perspectivas novedosas y prometedoras, que, si son reconocidas y profundizadas, pueden contribuir a despejar muchas de las incertidumbres de nuestra época.

Palabras clave: Vaticano II, Antropología, Recepción, Cristocentrismo.

Abstract: This articles attempts to take a critical look at II Vatican Council from the reception of its anthropological teaching in the pastoral-theological consideration of the synods of the diocese of Temuco. These synods, which were held in different times and were driven by varying social and ecclesial situations, express their own approaches to the understanding of council anthropology which sometimes contradict one another. It is possible to state that these inconclusive approaches relate to the ambiguity of II Vatican anthropology. In fact, the synods nourish from its richness but they also reflect its weaknesses and shortcomings. However, these same synods are testimony of the novel and promising perspectives that the Council planted which, if they are recognized and deepened, can contribute to clarify many of the uncertainties of our time.

Keywords: Vatican II, Anthropology, Reception, Christ-centrism. 